\title{
Tipologia de sistemas de produção baseada nas características do leite
}

\author{
Anselmo Bodenmüller Filho ${ }^{1}$, Julio Cesar Damasceno ${ }^{2}$, Isolde Terezinha Santos Previdelli ${ }^{3}$, \\ Rosangela Getirana Santana ${ }^{3}$, Carlos Eduardo Crispim de Oliveira Ramos ${ }^{2}$, Geraldo Tadeu \\ dos Santos ${ }^{2}$
}

1 Universidade Tecnológica Federal do Paraná.
2 Universidade Estadual de Maringá - Departamento de Zootecnia.
${ }^{3}$ Universidade Estadual de Maringá - Departamento de Estatística.

RESUMO - Objetivou-se propor uma metodologia de análise de sistemas de produção, tomando-se como base o fluxo quantitativo intra-anual e as características qualitativas do leite entregue pelos produtores de leite à indústria. Foram coletados dados referentes a 1.196 produtores de leite durante os anos 2005 e 2006 utilizando-se as variáveis produção mensal; teores de gordura, proteína, lactose e sólidos totais; contagem de células somáticas e contagem padrão em placas. A metodologia de análise utilizada foi a análise de componentes principais e a classificação hierárquica ascendente (tipologia). As variáveis mais importantes na construção do primeiro componente principal (CP1) são os teores de gordura, proteína e sólidos totais do leite, que explicaram 32,5\% da diversidade de sistemas de produção e podem ser consideradas indicadores da qualidade nutricional do leite. Na construção do segundo componente principal (CP2), as variáveis mais importantes são teor de lactose, contagem de células somáticas e contagem microbiana do leite, que explicaram 24,04\% da diversidade e representam a qualidade higiênica do leite. A distribuição intra-anual da produção não é importante para explicar a diversidade entre as unidades produtoras de leite. Para a tipologia dos sistemas de produção, foram considerados os três primeiros componentes principais, cuja explicação da variabilidade total foi de 70,52\%. As 1.196 propriedades rurais produtoras de leite pertencem a 17 grupos de sistemas de produção com características de qualidade do leite próprias.

Palavras-chave: análise multivariada, componentes principais, classificação hierárquica ascendente

\section{Typology of production systems based on the milk characteristics}

\begin{abstract}
The objective of the study was to propose a methodology of production systems analysis, considering intraannual quantitative flow and the qualitative characteristics of the milk delivered by the farmers to the industry. The data were collected from 1,196 milk producers from 2005 to 2006 using month production variables, fat content, protein, lactose and total solids, counting of somatic cells, and standardized counting in plates. The method of analysis used was the main component analyses and ascending hierarchical classification (typology). The most important variables in the construction of the first principal component (PC1) are fat content, protein and total milk solid contents, which explained 32.5\% of the diversity of production systems, and they can be considered as the indicator of milk nutritional quality. In the construction of the second principal component (PC2), the most important variables are lactose content, counting of somatic cells and milk microbial counting, which explained $24.04 \%$ of the diversity and represent the hygienic quality of the milk. The intra-annual distribution of the milk production is not important to explain the diversity among milk production units. For the production system typology, it was considered the first three main components whose explanation of the total variability was of $70.52 \%$. The 1,196 milk producing rural properties belong to the 17 groups of milk production systems with their own characteristics of milk quality.
\end{abstract}

Key Words: ascending hierarchical classification, main components, multivariate analysis

\section{Introdução}

A produção de leite no Brasil é de natureza complicada, pois depende de uma base constituída de elevado número de produtores de baixa escala de produção e grande diversidade de estratégias, impondo desafios à evolução dos sistemas de produção para a pesquisa, a extensão rural e as indústrias (Alves, 2000).

Normalmente, as indústrias contam com uma base de informações mensais das características do leite, tais como volume, teores de gordura, proteína, lactose e sólidos totais, contagem de células somáticas e contagem 
microbiana. Essas informações auxiliam na definição dos preços pagos aos produtores e nas ações de assistência técnica. Entretanto, a eficiência com que essa base de informações tem sido utilizada tem esbarrado na ausência de ferramentas de análise que simplifiquem o campo de ação.

Os resultados obtidos em propriedades leiteiras são construídos a partir do desempenho dos animais associados às práticas cotidianas ou esporádicas realizadas pelo homem (Chevereau, 2004). Se os resultados são materializados por meio das práticas, e há diversidade de resultados, existe, em tese, diversidade de combinações de estratégias. Gilibert \& Courbon (1990) propuseram um protocolo de análise de sistemas de produção entendendo o fluxo do leite como elo comum que liga os elementos da cadeia produtiva e caracteriza-se por informações quantitativas e qualitativas. A indústria considera a matéria-prima leite por seu volume, distribuição intra-anual e qualidade nutricional e higiênicosanitária.

Na análise de sistemas de produção elege-se a análise de componentes principais (ACP) pela sua capacidade de síntese de grandes tabelas de dados e por indicar as variáveis responsáveis pela diversidade dos sistemas de produção (Smith et al., 2002; Mburu et al., 2007). A tipologia proposta visa caracterizar grupos homogêneos de sistemas leiteiros para que se proceda a ação compatível segundo suas especificidades.

Este trabalho foi conduzido com o objetivo de tipificar propriedades rurais, da forma mais homogênea possível, a partir das características do leite recebido pela indústria, e identificar quais características do leite que mais explicam as diferenças entre os sistemas de produção.

\section{Material e Métodos}

O presente estudo envolveu a observação do fluxo do leite da empresa Agroindustrial Cooperativa Central (CONFEPAR), sediada em Londrina, Paraná. Os dados quantitativos e qualitativos dos produtores de leite foram originados a partir dos laudos oficiais que trazem informações microbiológicas, físicas, químicas, de contagem de células somáticas e de resíduos químicos.

O Departamento de Captação da empresa disponibilizou os resultados analíticos do período de agosto de 2005 a outubro de 2006. Em maio de 2006, foi lançado o Programa de Melhoria da Qualidade do Leite, sob apoio do Programa de Transferência de Tecnologias ao Produtor. Essa fase se refere ao período de implantação do trabalho de amostragem padronizada que continha resultados de 2619 fornecedores. Como critério preliminar, decidiu-se que, do total de análises realizadas, somente seriam utilizados os resultados analíticos sequenciais de no mínimo doze amostras mensais, repercutindo a dispersão durante as estações do ano. Dessa forma, nove regiões de captação que continham informações necessárias foram selecionadas. Não foi considerado o leite de conjunto de produtores, a fim de refletir a uniformidade particular de cada estabelecimento. A partir desses critérios, selecionaram-se, ao final, 1196 produtores individuais.

A base de dados original continha as seguintes informações: o código do entreposto, a data da amostragem, a linha (rota) de coleta, o código do produtor, os teores de gordura, proteína, lactose e sólidos totais, a contagem de células somáticas, o volume do dia da amostragem e contagem padrão em placas. Uma nova planilha foi criada a partir dos dados iniciais, em que foram calculados e inseridos os volumes médios mensais. Foram ignorados os teores de gordura abaixo de $2 \mathrm{~g} / 100 \mathrm{~g}$ e acima de $6 \mathrm{~g} / 100 \mathrm{~g}$, assumindo-se que representavam erros de amostragem e/ ou analíticos.

A partir da modelagem preliminar, que contém a análise descritiva dos dados, foram calculadas as médias com os respectivos desvios padrões e coeficientes de variação. Foi representada em gráfico tipo box plot a variável produção de leite para destacar a diversidade de valores.

Segundo Moita Neto \& Moita (1997), a análise fatorial em componentes principais (ACP) consiste em escrever as coordenadas das amostras em outro sistema de eixos mais conveniente. Por meio de combinações lineares das $n$ variáveis, geram-se $n$ componentes principais em ordem decrescente de máxima variância. A análise fatorial permite reduzir a dimensionalidade dos pontos representativos das amostras e julgar a importância das variáveis originais. O gráfico (Figura 3) da componente principal 1 versus a componente principal 2 forneceu os pontos no espaço $n$ dimensional. As variáveis consideradas nessa análise foram produção de leite, teores de gordura, proteína, lactose e sólidos totais do leite, contagem de células somáticas, contagem padrão em placas e a distribuição intra-anual do leite. Adicionalmente, foram feitas a interpretação dos pontos no gráfico e a identificação das variáveis de maior peso na combinação linear. Por fim, apresentaram-se as correlações entre as variáveis constituintes dos sete componentes principais.

A etapa seguinte do trabalho consistiu em agrupar as unidades de produção por classificação hierárquica ascendente (análise de cluster) utilizando-se as três primeiras dimensões dos componentes principais. Esse método mostrou-se efetivo para resolver o problema de como organizar informações multivariadas, sendo utilizado o critério de menor redução da variância total da matriz (Lebart et al., 2004). 
De acordo com Carvalho \& Struchiner (1992), as unidades são agrupadas de duas em duas, repetindo-se o processo para a união dos pequenos grupos até a construção de uma árvore de classificação. Tais estruturas denominadas taxonomias ou tipologias compõem os grupos (conglomerados ou constelações) em que os indivíduos da população são ordenados. O índice de agregação (similaridade) corresponde à distância qui-quadrado ponderada entre as classes. Esses índices são representados na hierarquia por um gráfico de barras (dendrograma). Realizou-se um corte de tal forma que a variância intraclasses (dentro de cada grupo) ficou em $23 \%$ (menor que 25\%, caracterizando grupos homogêneos) e a variância interclasses, em $76 \%$ (acima de $75 \%$, caracterizando grupos heterogêneos). A cada rodada foi retirado da análise o grupo homogêneo e novamente repetiram-se os procedimentos até identificar os dezessete grupos. Estas são novas variáveis onde todas as unidades foram alocadas nas respectivas classes, que podem ser situadas no mesmo espaço gráfico definido pela análise de componentes principais. Em seguida, procedeu-se a representação em um novo gráfico que relaciona os componentes principais 1 e 2 aos dezessete grupos.

As análises estatísticas foram realizadas mediante uso do software STATISTICA ${ }^{\circledR}$, versão 7.0, licenciado pela Universidade Estadual de Maringá (STATISTICA, 2007).

\section{Resultados e Discussão}

De acordo com informações referentes ao Programa de Melhoria da Qualidade do Leite da CONFEPAR, em respeito à legislação vigente, todo fornecedor está obrigado a adequar-se às novas exigências. O programa de pagamento pela qualidade proporcionou a bonificação do preço do litro e repercutiu o sucesso dos trabalhos técnicos de campo. Dessa forma, o padrão de qualidade foi assegurado mesmo se tratando de uma fase de transição para a empresa e seus cooperados.

A análise descritiva proporciona um perfil de resultados no qual é cabível uma série de apontamentos sobre os valores encontrados (Tabela 1). A distribuição intra-anual da produção de leite não contribuiu para explicação da variabilidade dos sistemas de produção, motivo pelo qual foi retirada da análise.

A presença de dados excessivamente altos ou baixos provocou assimetria na distribuição das frequências. Assim, as médias se deslocaram na direção dos valores aberrantes impedindo-as de serem medidas preferíveis de tendência central. As medianas expressaram as posições centralizadas em relação à distribuição dos dados. Segundo Hair Jr. et al. (2005), os pontos fora de padrão ou isolados (outliers) não são benéficos tampouco problemáticos, mas devem ser observados dentro do contexto da análise e avaliados em função da informação que poderão fornecer. Os teores de gordura, proteína, lactose e sólidos totais foram assinalados por mediana, faixa dos $50 \%$ de dados centrais, leque dos valores não isolados (non outlier range) e os valores fora de padrão (outliers) (Figura 1).

Os pontos fora de padrão contribuíram para evidenciar a ação de múltiplos fatores sobre as análises. No trabalho de Noro et al. (2006), em rebanhos de raça holandesa na região Sul do Brasil, existem importantes influências das variações ambientais no estudo da composição do leite. Segundo Carvalho (2000), a seleção genética, a identificação

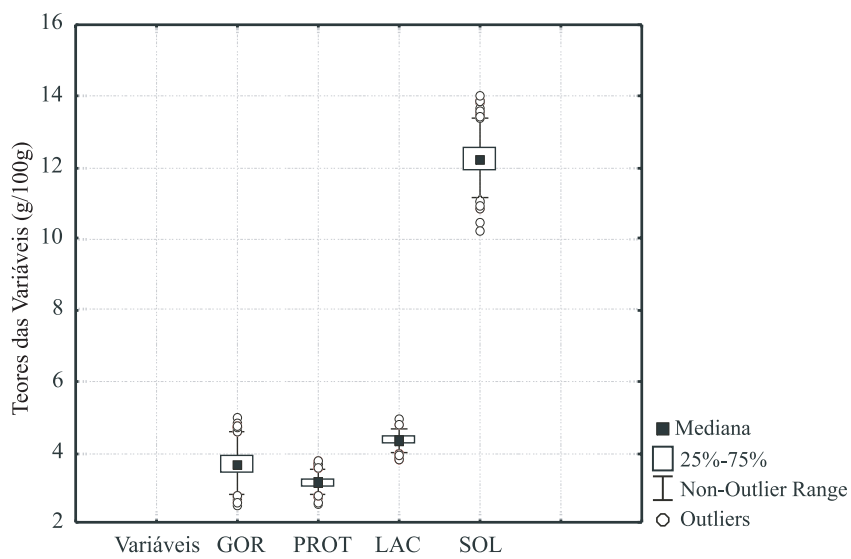

Figura 1 - Box-plot dos constituintes nutricionais do leite ou variáveis originais: gordura, proteína, lactose e sólidos totais.

Tabela 1 - Análise descritivas das variáveis $(\mathrm{n}=1.196)$

\begin{tabular}{|c|c|c|c|c|c|c|}
\hline Item & Média & Mediana & Mínimo & Máximo & Desvio-padrão & $\mathrm{CV} \%$ \\
\hline Gordura (g/100 g) & 3,72 & 3,70 & 2,48 & 5,4 & 0,346 & 9,30 \\
\hline Lactose $(\mathrm{g} / 100 \mathrm{~g})$ & 4,36 & 4,37 & 3,10 & 5,0 & 0,148 & 3,40 \\
\hline Sólidos totais (g/100 g) & 12,27 & 12,25 & 10,24 & 15,0 & 0,469 & 3,82 \\
\hline Contagem de células somáticas $(1.000 \mathrm{CS} / \mathrm{mL})$ & 555,32 & 497,35 & 12,76 & 2589,4 & 308,912 & 55,63 \\
\hline Contagem padrão de placas (1.000 ufc/mL) & 2635,83 & 1948,48 & 5,58 & 16457,2 & 2454,179 & 93,11 \\
\hline
\end{tabular}


e a manipulação dos genes que controlam a composição e a nutrição afetam a composição do leite cru. Para Durr et al. (2001), a interpretação dos resultados depende, principalmente, da precisão da amostragem, da manipulação das amostras e do método analítico. Em virtude dos fatores de impacto citados, para uma proposta de análise univariada, os resultados podem ser utilizados segundo a finalidade desejada. Contudo, para relacionar as estratégias dos produtores e as práticas de manejo com tais resultados, supondo estarem em dependência direta dos sistemas de produção, outras técnicas estatísticas foram utilizadas.

O gráfico box-plot (Figura 2), mais adequado para se observar a diversidade, proporciona melhor visualização da base de dados, onde valores extremos da produção de leite foram excluídos para melhorar a visualização, uma vez que o coeficiente de variação foi bastante alto.

O valor da mediana encontrado (2.495,36 L/produtor/ mês) indica que possivelmente existam semelhanças típicas aos resultados de Assis et al. (2005). De acordo com esses autores, o extrato de produção até $100 \mathrm{~L} /$ fazenda/dia (3000 L/fazenda/mês) e de até $1200 \mathrm{~L} /$ vaca ordenhada/ano predomina no Brasil, onde a maioria adota o sistema extensivo. Em virtude dessa classificação, pode-se ressaltar a importância do elevado número de produtores e a grande participação no total de leite fornecido ao laticínio.

O limite da CCS foi estipulado no máximo em 1 milhão de CS/mL, de julho de 2005 a julho de 2008, segundo a Instrução Normativa n ${ }^{0} 51$ (2002), para a região Sul e Sudeste para o leite cru refrigerado. Para a contagem padrão em placas, o limite é de um milhão de ufc/mL. A Resolução 065 (2005) definiu, até julho de 2008, para requisitos microbiológicos, omáximo total debactérias em 750.000 ufc/mLe $750.000 \mathrm{CS} / \mathrm{mL}$. Verificou-se que a mediana da variável CCS está próxima da média e seus valores estão dentro dos padrões aceitáveis.

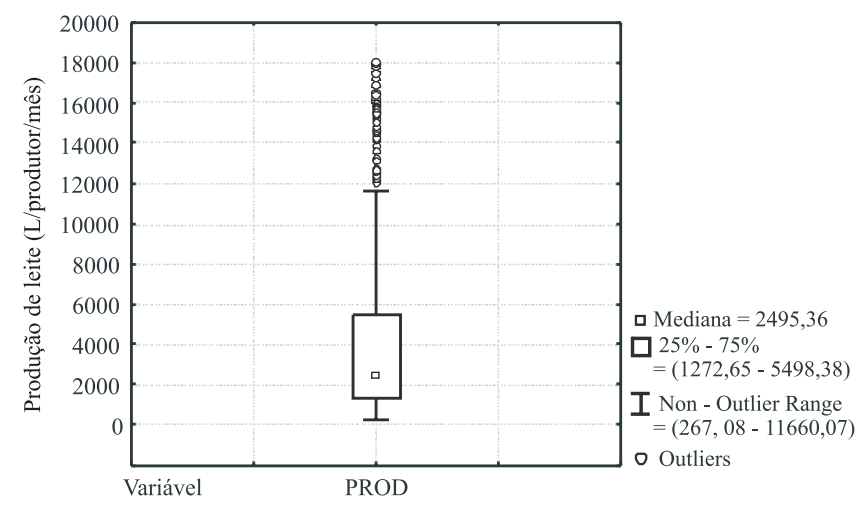

Figura 2 - Box-plot da variável produção de leite.
De acordo com Zanela et al. (2006), os sistemas de produção, classificados em especializado, semiespecializado e não especializado, têm apenas $41,8 \%$ das amostras dentro dos limites. A maior especialização dos sistemas resultou em aumento da produção e menor CCS. Para esses autores, características regionais deveriam ser consideradas no estabelecimento dos padrões de composição do leite. Os maiores valores da caseína, lactose e sólidos desengordurados foram determinados pelo melhor manejo nutricional e higiene na ordenha. A prescrição das valiosas práticas preventivas sobre a qualidade higiênica pelos técnicos de campo, subsidiadas pelas análises laboratoriais, desencadearam alterações positivas nos resultados ora expostos. Para a variável ufc, poucos resultados ficaram abaixo do exigido, indicando que essa característica do leite merece atenção especial por parte da indústria e da assistência técnica.

Pode-se notar que o primeiro componente principal (CP1) explica 32,50\% da variância, o segundo (CP2) explica 24,04\% e o terceiro (CP3), 14,00\%, totalizando para os três primeiros componentes 70,52\% (Tabela 2).

Para facilitar o entendimento da técnica estatística empregada, a argumentação ficou limitada nos componentes principais 1 e 2 , com a variabilidade capturada de $56,51 \%$, enquanto a baixa participação do terceiro componente possibilitará discussões específicas quando forem necessárias. Graças ao resultado da variância total acumulada comparado aos trabalhos que aplicaram as mesmas técnicas, pode-se afirmar que esse valor não é muito comum na área da Zootecnia. A aplicação de análise de componentes principais por Aleixo et al. (2007) atingiu $52,76 \%$ da variância acumulada quando analisou os três primeiros fatores para determinar grupos homogêneos de produtores de leite. Segundo Betancourt et al. (2005), aplicando metodologia semelhante alcançou-se $45 \%$ da variância acumulada no primeiro plano fatorial (componentes 1 e 2). De maneira semelhante, como pode ser verificado nos estudos de Sraïri \& Lyoubi (2003) e Sraïri \& Kiade (2003), os resultados foram de 63,3\% e 72,6\% de variância acumulada, respectivamente para os três primeiros componentes.

De acordo com Barroso \& Artes (2003), se uma alta porcentagem da variabilidade total for explicada pelos componentes principais (fatores), é possível usá-los no lugar das variáveis originais sem perder muita informação. Para apoiar a compreensão da técnica utilizada, Carvalho \& Struchiner (1992) conceituaram que as categorias das variáveis configuram uma nuvem de pontos em um espaço multidimensional, o que gera impedimento para inspeção visual. A solução desse problema é dada matematicamente pelos autovetores da matriz de dados. A importância do 
percentual da variância total da matriz é refletida na capacidade de cada eixo representar a dispersão. O valor percentual sendo elevado possibilita a melhor representação da distribuição dos pontos no espaço e, consequentemente, das relações existentes entre as variáveis.

À luz da formação das projeções, as variáveis que marcaram o plano fatorial exibiram as correlações inerentes aos componentes principais. Pode-se notar a alta correlação das variáveis que constituem a qualidade nutricional (Figura 3).

Conforme reportado por Smith et al. (2002), considerações podem ser feitas em função do ângulo entre os vetores. Se próximo a zero, a correlação é muito alta e positiva; se for próximo a $180^{\circ}$, a correlação é também alta, porém negativa; finalmente, se o ângulo é cerca de $90^{\circ}$, as variáveis estão pouco relacionadas. Nota-se a correlação forte entre contagem de células somáticas e contagem padrão em placas, constando como oponente o maior ângulo entre produção de leite e contagem de células somáticas e/ ou contagem padrão em placas. Figurando em quadrantes opostos, com ângulo próximo a $180^{\circ}$, presume-se que quanto maior a produção de leite, melhor qualidade higiênica do leite. De maneira semelhante, quanto maior contagem de células somáticas e contagem microbiana, menor lactose, indicando haver comprometimento dos teores de lactose à medida que a higiene do leite é afetada.

Conforme os valores apontados, pode-se verificar o peso que cada variável carrega sobre a componente principal (Tabela 3). As variáveis mais correlacionadas são as mais importantes na construção dos respectivos componentes. As variáveis mais importantes na construção da variável sintética CP1 são gordura, proteína e sólidos totais, enquanto lactose, contagem de células somáticas e contagem padrão em placas são as mais importantes na construção do CP2 e na produção de leite para CP3. Assim, a variável sintética CP1 é um indicador da qualidade nutricional do leite. A variável sintética CP2 seria um indicador da qualidade higiênico-sanitária do leite.

Tabela 2 - Autovalores e percentagem de explicação da variância total

\begin{tabular}{lccc}
\hline $\begin{array}{l}\text { Componente } \\
\text { principal }\end{array}$ & Autovalor & \% da variância & \% acumulada \\
\hline 1 & 2,2728 & 32,4687 & 32,468 \\
2 & 1,6803 & 24,0434 & 56,512 \\
3 & 0,9806 & 14,0084 & 70,520 \\
4 & 0,8606 & 12,2944 & 82,815 \\
5 & 0,6946 & 9,9232 & 92,738 \\
6 & 0,4773 & 6,8183 & 99,556 \\
7 & 0,03103 & 0,44337 & 100,00 \\
\hline
\end{tabular}

Os valores das médias dos clusters podem auxiliar na discussão sobre o direcionamento da assistência técnica, visando ao aconselhamento específico (Tabela 4). A análise de classificação hierárquica ascendente permitiu reduzir o universo inicial de 1196 sistemas de produção para dezessete grupos de sistemas. Os quadrantes obtidos a partir da intersecção dos eixos CP1 e CP2 permitem interpretar os grupos de sistemas segundo as características nutricionais e as higiênicas sanitárias do leite (Figura 4).

No quadrante representado por valores negativos de CP1 e CP2 (quadrante 1), localizam-se os grupos que produzem leite de pior qualidade nutricional e higiênicosanitária dentre os casos estudados. No quadrante formado por valores negativos de CP1 e positivos de CP2 (quadrante 2), encontram-se grupos de produtores cujo leite produzido apresenta qualidade higiênico-sanitária superior, mas baixa qualidade nutricional. Essa região do gráfico é marcada por sistemas mais produtivos, onde possivelmente predominam raças leiteiras especializadas, no entanto com menor teor de sólidos totais. Encontram-se os clusters 6, 7 e 8 com produções superiores à média dos demais sistemas. O posicionamento atípico do grupo 7 no plano fatorial se deve à alta produção mensal, possivelmente sob sistemas intensivos com rebanhos estabulados. Embora de menor importância para a formação dos eixos CP1 eCP2, a magnitude das diferenças da produção desse grupo de produtores em

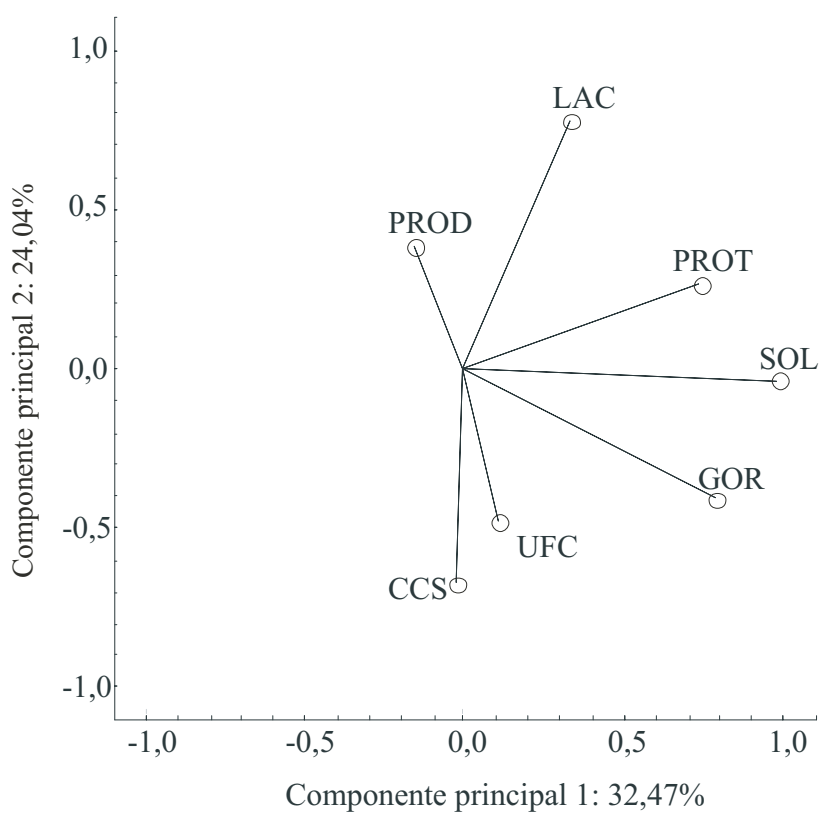

Figura 3 - Projeção das variáveis: produção de leite, gordura, proteína, lactose, sólidos totais, contagem de células somáticas e contagem padrão em placas no plano definido por CP1 e CP2. 
relação aos demais fez com que a variável produção de leite fosse determinante na localização desse grupo e, em menor grau, dos grupos 6 e 8 .

No quadrante formado por valores positivos de CP1 e negativos de CP2 (quadrante 3), encontram-se grupos de produtores cujo leite é de bom padrão nutricional, mas de qualidade higiênico-sanitária insatisfatória. Já no quadrante 4, formado pelos valores positivos de CP1 e CP2, localizamse grupos de produtores cujo leite produzido é de padrão higiênico-sanitário e qualidade nutricional relativamente superior dentre os casos estudados.

Portanto, pode-se constatar que dentre os casos estudados há aqueles posicionados no quadrante 4 que podem servir de referencial positivo para os demais sistemas de produção, uma vez que apresentam leite com padrão higiênico-sanitário e nutricional relativamente superior, e, como possuem padrões produtivos diferenciados, poderiam servir de base para as ações de assistência técnica por parte da indústria. Os caminhos a serem trilhados pelos diferentes grupos de produtores na busca pela melhor qualidade do leite produzido são distintos e dependem da posição dos grupos no plano CP1 e CP2.

Note que há apenas três grupos de produtores localizados no quadrante 4 (grupos 11, 12 e 16) e ainda ocupam posição central no gráfico, não havendo qualquer caso ocupando posição extrema nesse quadrante (elevada qualidade nutricional e higiênico-sanitária do leite). Isso indica haver espaço para melhora considerável de qualidade nutricional e higiênico-sanitária nesses grupos de produtores. Os grupos 14 (elevados teores de gordura, proteína e sólidos totais) e 8 (baixos valores de contagem de células somáticas e contagem padrão em placas) poderão servir como referenciais positivos de qualidade nutricional e higiênicosanitária do leite, respectivamente, nas estratégias da assistência técnica em propor ações de melhorias aos demais grupos. Ressalta-se que a qualidade do leite é produto das práticas realizadas pelo produtor, sobretudo no que se referem ao padrão genético dos animais, práticas de alimentação, manejo sanitário dos animais e manejo de ordenha.

Tabela 3 - Correlação entre as variáveis e os componentes principais

\begin{tabular}{lrrr}
\hline Variável & CP1 & CP2 & \multicolumn{1}{c}{ CP3 } \\
\hline Produção de leite & $-0,1614$ & 0,3909 & $-0,6898$ \\
Gordura & 0,7906 & $-0,4089$ & $-0,1783$ \\
Proteína & 0,7369 & 0,2691 & 0,0135 \\
Lactose & 0,3281 & 0,7772 & 0,1320 \\
Sólidos totais & 0,9788 & $-0,0353$ & $-0,0908$ \\
Contagem de células somáticas & $-0,0289$ & $-0,6751$ & $-0,4679$ \\
Contagem padrão em placas (ufc) & 0,1082 & $-0,4788$ & 0,4775 \\
\hline
\end{tabular}

Enquadrando-se os problemas de composição química deficiente, conforme os padrões estabelecidos na Resolução (2005), verificou-se que no grupo 3 os níveis encontrados para proteína foram críticos (proteína mínima de 2,90g/100g) e inferiores ao mínimo de sólidos totais (extrato seco total mínimo de 11,4 g/100 g). Propostas a serem investigadas para direcionar o conselho técnico poderiam se fundamentar na composição da genética dos rebanhos. O grau de sangue dos reprodutores, o uso de raças que naturalmente produzem mais sólidos (Jersey) ou touros selecionados para aumento do teor de sólidos, além da seleção de animais resistentes para as condições tropicais (West, 2003), podem ser citados. O estresse calórico pode diminuir o teor de proteína do leite, pela queda no consumo de matéria seca, conferindo a influência direta da dieta na composição (Carvalho, 2000). Segundo esse autor, a disponibilidade de energia na dieta poderia ser insuficiente, ou outros fatores relacionados, como a falta de proteína degradável no rúmen e de carboidratos não estruturais, e o excesso de fibra em detergente neutro, os quais limitariam a síntese de proteína microbiana no rúmen. Esses estabelecimentos deveriam proporcionar ou reavaliar o conforto térmico ideal para os rebanhos. Outras práticas de manejo alimentar, como fornecimento de alimentos nas horas mais frescas do dia, aumento da frequência de alimentação e acesso a água, estão entre as alternativas a serem propostas. Na prática, deveria ser implantado um plano de suplementação alimentar. O grupo 14 destaca-se pelos altos teores de gordura, proteína e sólidos totais, aproximando-se ao grupo 3 na escala de produção. O enfoque técnico que prioriza a produção de sólidos pode encontrar boas referências nesses exemplos.

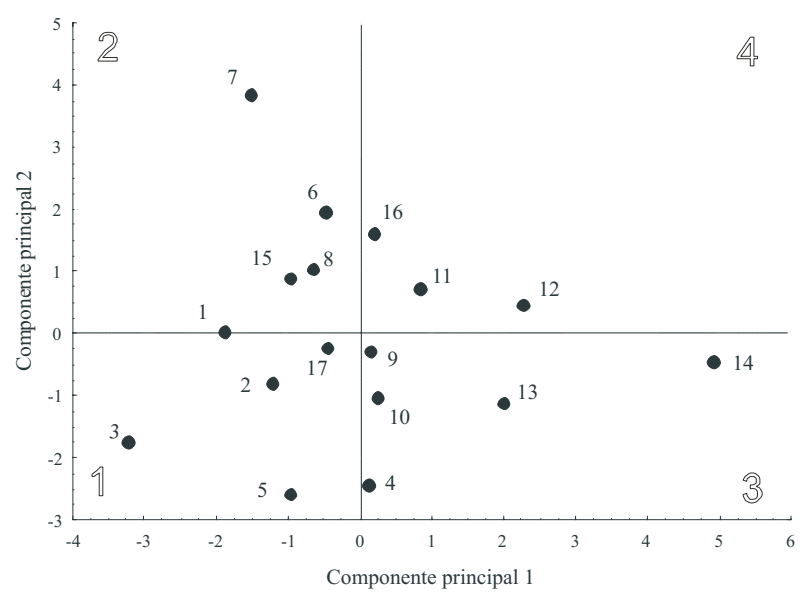

Figura 4 - Representação gráfica dos grupos de sistemas de produção no plano fatorial a partir da intersecção dos eixos CP1 e CP2. 
Os índices de eficiência particulares podem sugerir adaptações viáveis aos sistemas similares. Nos grupos 3, 4 e 5, os níveis de lactose foram 4,06, 4,18 e 4,02 g/100 g, respectivamente. De acordo com a Resolução 065 (2005), a lactose deve ter o mínimo de 4,30 g/100 g. Vacas com processos inflamatórios mamários sofrem significativa diminuição da produção de leite e aumento da contagem de células somáticas (Carvalho et al., 2002). Conforme Muller (2002), a mastite provoca aumento da contagem de células somáticas e alterações em gordura, proteína e lactose. O efeito de altas contagens de células somáticas e a elevada carga microbiana sobre a composição do leite pode explicar as baixas médias de lactose. De acordo com Paula et al. (2004), os efeitos de microrregião, ano e mês da análise e idade da amostra influenciaram a contagem de células somáticas, sofrendo, ainda, efeitos do rebanho e nível de produção. Em virtude dos valores críticos da contagem de células somáticas para tais agrupamentos, é possível, mediante o monitoramento e o incentivo pela qualidade, que o trabalho técnico reforce medidas preventivas e corretivas da mastite.

O grupo 16 merece atenção devido à baixa contagem de células somáticas, à alta lactose e ao alto teor de sólidos, com baixo volume mensal. Extrapolando para os níveis de contagem de células somáticas recomendáveis no futuro próximo, verifica-se que os grupos $11,12,15,16$ e 17, caracterizados por média e baixa produção, são os que têm a menor incidência de mastite no rebanho (menor que o limite de $400 \mathrm{mil} \mathrm{CS} / \mathrm{mL}$ ). Sugere-se, também, maior enfoque nas práticas preventivas aplicadas por tais grupos, uma vez que as simples práticas de manejo higiênico já são adotadas e deveriam ser difundidas como argumentos para maior eficácia nos trabalhos de campo. Entretanto, esses mesmos grupos são úteis em mostrar que mesmo em condições de baixos valores de contagem de células somáticas há casos de elevados valores de contagem padrão em placas, indicando haver necessidade de se enfatizar as práticas de higiene no momento da ordenha e rigorosa assepsia dos equipamentos para esses e os demais grupos.

Embora a presente pesquisa não traga informações das características dos sistemas de produção no que diz respeito a estrutura da propriedade, plantel e maneira como os produtores mobilizam e atuam sobre os fatores de produção, a tipologia realizada a partir das características do leite se mostra uma ferramenta útil na ação da assistência técnica e na definição de estratégias por parte da indústria. Pressupõe-se que propriedades rurais pertencentes ao mesmo grupo, considerando-se as características do leite, assemelhem-se quanto aos meios pelos quais essa qualidade do leite foi construída, permitindo aos agentes de ATER e à indústria ajustar melhor suas estratégias de ação sobre o grupo, segundo a posição que ocupa no plano fatorial formado.

Ressalta-se que a diferenciação do conselho técnico e as estratégias de ação para melhoria da qualidade do leite para grupos distintos de produtores devem ser pautadas nas variáveis mais importantes para a construção dos primeiros componentes principais. As demais variáveis devem ser consideradas, mas de forma geral para todos os grupos de produtores.

Nesse sentido, para se agir sobre um dado grupo posicionado no quadrante 1, por exemplo, deverão ser priorizadas ações, tanto na qualidade nutricional quanto na higiênico-sanitária do leite, enquanto para determinado grupo no quadrante 2 deve-se dar mais peso às ações de melhoria da qualidade nutricional do leite utilizando-se,

Tabela 4 - Médias dos grupos de sistemas de produção para as variáveis originais

\begin{tabular}{|c|c|c|c|c|c|c|c|c|}
\hline Grupo & $\begin{array}{l}\mathrm{N} \underline{\mathrm{o}} \\
\text { produtores }\end{array}$ & $\begin{array}{l}\text { Produção de leite } \\
\text { (L/produtor/mês) }\end{array}$ & $\begin{array}{l}\text { Gordura } \\
(\mathrm{g} / 100 \mathrm{~g})\end{array}$ & $\begin{array}{l}\text { Proteína } \\
\text { (g/100 g) }\end{array}$ & $\begin{array}{l}\text { Lactose } \\
(\mathrm{g} / 100 \mathrm{~g})\end{array}$ & $\begin{array}{l}\text { Sólidos totais } \\
\text { (g/100 g) }\end{array}$ & $\begin{array}{l}\text { Contagem de } \\
\text { células somáticas } \\
(1.000 \mathrm{CS} / \mathrm{mL})\end{array}$ & $\begin{array}{c}\text { Contagem padrão } \\
\text { em placas } \\
(1.000 \mathrm{ufc} / \mathrm{mL})\end{array}$ \\
\hline 1 & 93 & 4.073 & 3,37 & 3,05 & 4,32 & 11,67 & 533 & 2211 \\
\hline 2 & 58 & 4.055 & 3,59 & 3,09 & 4,24 & 11,90 & 778 & 1951 \\
\hline 3 & 28 & 2.826 & 3,35 & 2,92 & 4,06 & 11,25 & 695 & 4179 \\
\hline 4 & 51 & 1.564 & 3,97 & 3,15 & 4,18 & 12,37 & 1321 & 2561 \\
\hline 5 & 33 & 1.963 & 3,81 & 3,06 & 4,02 & 12,08 & 854 & 4843 \\
\hline 6 & 14 & 48.900 & 3,66 & 3,20 & 4,45 & 12,27 & 555 & 1645 \\
\hline 7 & 4 & 109.703 & 3,48 & 3,23 & 4,45 & 12,10 & 596 & 3093 \\
\hline 8 & 94 & 18.132 & 3,54 & 3,19 & 4,41 & 12,10 & 561 & 762 \\
\hline 9 & 141 & 3.287 & 3,82 & 3,19 & 4,33 & 12,31 & 648 & 1561 \\
\hline 10 & 85 & 1.793 & 3,89 & 3,17 & 4,28 & 12,35 & 613 & 4594 \\
\hline 11 & 135 & 4.058 & 3,81 & 3,27 & 4,45 & 12,51 & 387 & 1780 \\
\hline 12 & 61 & 1.783 & 4,11 & 3,38 & 4,45 & 12,94 & 377 & 2179 \\
\hline 13 & 95 & 2.010 & 4,18 & 3,32 & 4,34 & 12,87 & 707 & 5230 \\
\hline 14 & 18 & 2.079 & 4,70 & 3,57 & 4,42 & 13,80 & 693 & 2056 \\
\hline 15 & 124 & 4.579 & 3,43 & 3,15 & 4,42 & 11,95 & 381 & 1508 \\
\hline 16 & 107 & 3.809 & 3,46 & 3,30 & 4,52 & 12,27 & 250 & 1835 \\
\hline 17 & 55 & 2.253 & 3,50 & 3,18 & 4,38 & 12,05 & 352 & 7600 \\
\hline
\end{tabular}


para ambos os casos, referenciais dentro da própria população de produtores estudada.

\section{Conclusões}

A aplicação das técnicas de estatística multivariada mostra-se uma metodologia apropriada na abordagem sobre a diversidade dos sistemas produtivos de leite. O primeiro componente principal explica 32,47\% da variância total e é o indicador da qualidade nutricional do leite. O segundo componente principal explica 24,04\% da variância total e é o indicador higiênico-sanitário do leite. A representação gráfica dos clusters no plano fatorial identifica as famílias dispersas nos quadrantes. As 1196 propriedades rurais produtoras de leite pertencem a 17 grupos de sistemas de produção. A tipologia simplifica o campo de visão do universo de produtores rurais e permite à indústria definir estratégias mais precisas para a melhoria da qualidade do leite de seus fornecedores.

\section{Agradecimentos}

Os autores agradecem a Agroindustrial Cooperativa Central (CONFEPAR), sediada em Londrina, PR, pela disponibilização dos dados para este estudo, como também ao Sr. Marcelo de Rezende, coordenador do Programa de Transferência de Tecnologias ao Produtor, pela fundamental colaboração.

\section{Referências}

ALEIXO, S.S.; SOUZA, J.G.; FERRAUDO, A.S. Técnicas de análise multivariada na determinação de grupos homogêneos de produtores de leite. Revista Brasileira de Zootecnia, v.36, n.6, p.2168-2175, 2007 (supl.).

ALVES, E.R.A. Fatores que interferem na transferência e adoção de tecnologia na atividade leiteira. In: SIMPÓSIO SUSTENTABILIDADE DA PECUÁRIA DE LEITE NO BRASIL, 2000, Goiânia. Anais... Juiz de Fora: Embrapa Gado de Leite, 2000. p.175-191.

ASSIS, A.G.; STOCK, L.A.; CAMPOS, O.F. et al. Sistemas de produção de leite no Brasil. Juiz de Fora: Embrapa Gado de Leite, 2005. 6p. (Circular Técnica, 85).

BARROSO, L.P.; ARTES, R. Análise multivariada. In: SIMPÓSIO DE ESTATÍSTICA APLICADA À EXPERIMENTAÇÃO AGRONÔMICA, 10., 2003, Lavras. Anais... Lavras: Universidade Federal de Lavras, 2003. p.152.

BETANCOURT, K.; IBRAHIM, M.; VILLANUEVA, C. et al. Caracterización del manejo productivo de sistemas lecheros en la cuenca del río Bulbul de Matiguás, Matagalpa, Nicaragua. Livestock Research for Rural Development, v.17, n.80, 2005.

CARVALHO, G.F.; CUNHA, R.P.L.; MOLINA, L.R. et al. Milk yield, somatic cell count and physico-chemical characteristics of raw milk collected from dairy cows in Minas Gerais State. In: CONGRESSO PANAMERICANO DE QUALIDADE DO LEITE
E CONTROLE DA MASTITE, 2., 2002, Ribeirão Preto. Anais... Ribeirão Preto, 2002. (CD-ROM).

CARVALHO, M.P. Manipulação da composição do leite por meio do balanceamento de dietas de vacas leiteiras. In: Qualidade do leite e controle de mastite. São Paulo: Lemos Editorial, 2000. p.163-168.

CARVALHO, M.S.; STRUCHINER, C.J. Análise de correspondência: Uma aplicação do método à avaliação de serviços de vacinação. Caderno de Saúde Pública, v.8, n.3, p.287-301, 1992.

CHEVEREAU, C. Pilotage stratégique des troupeaux laitiers. 2004. 345f. Dissertação Memoire d'Ingeniur (Graduation) École Supérieure d'Agriculture, Toulouse.

DÜRR, J.W.; FONTANELI, R.S.; MORO, D.V. Determinação laboratorial dos componentes do leite. In: GONZÁLEZ, F.H.D.; DÜRR, J.W.; FONTANELI, R.S. (Eds.) Uso do leite para monitorar a nutrição e o metabolismo de vacas leiteiras. Porto Alegre: Universidade Federal do Rio Grande do Sul, 2001. p.22-28.

GILIBERT, J.; COURBON, D. D’elevage regional: qualification des elevages selon lês types de livraison de lait. Le Roblillard, Lieury: INRA Productions Animales, Unité de recherches sur lês systèmes herbagers normands, 1990. p.379-386.

HAIR JR., J.F.; BABIN, J.B.; ANDERSON, R.E. et al. Multivariate data analysis. 6.ed. Upper Saddle River: Prentice Hall, 2005. 928p.

Instrução Normativa $n^{\circ} 51$ [2002]. Disponível em: <http://extranet. agricultura.gov.br/sislegis-consulta/consultar Legislacao.do? operacao=visualizar\&id=8932 > Acesso em: 07/11/2007.

LEBART, L.; MORINEAU, A.; PIRON, M. Statistique exploratoire multidimensionnelle. 3.ed. Paris: Dunod, 2004. 439p.

MBURU, L.M.; WAKHUNGU, J.W.; KANG'ETHE, W.G. Characterization of smallholder dairy production systems for livestock improvement in Kenya highlands. Livestock Research for Rural Development, v.19, n.8, artigo 110, 2007.

MOITA NETO, J.M.; MOITA, G.C. Uma introdução à análise exploratória de dados multivariados. Química Nova, v.21, n.4, p.467-469, 1997.

MULLER, E.E. Qualidade do leite, células somáticas e prevenção da mastite. In: SIMPÓSIO SUSTENTABILIDADE DA PECUÁRIA LEITEIRA NA REGIÃO SUL DO BRASIL, 2., 2002, Toledo. Anais... Maringá: Universidade Estadual de Maringá, 2002. p.206-217.

NORO, G.; GONZÁLEZ, F.H.D.; CAMPOS, R. et al. Fatores ambientais que afetam a produção e a composição do leite em rebanhos assistidos por cooperativas no Rio Grande do Sul. Revista Brasileira de Zootecnia, v.35, n.3, p.1129-1135, 2006.

PAULA, M.C.; RIBAS, N.P.; MONARDES, H.G. et al. Contagem de células somáticas em amostras de leite. Revista Brasileira de Zootecnia, v.33, n.5, p.1303-1308, 2004.

Resolução 065 [2005]. Regulamento da inspeção sanitária e industrial para leite e seus derivados. Disponível em: $<$ http://www.seab.pr.gov.br/arquivos/File/PDF/resol_56_ leite.pdf>. Acesso em: 7/11/2007.

SMITH, R.R.; MOREIRA, L.V.H.; LATRILLE, L.L. Characterization of dairy productive systems in the Tenth Region of Chile using multivariate analysis. Agricultura Técnica, v.62, n.3, p.35-395, 2002.

SRAÏRI, M.T.; LYOUBI, R. Typology of dairy farmings systems in Rabat suburban region, Marroco. Archivos de Zootecnia, v.52, p.47-58, 2003.

SRAÏRI, M.T.; KIADE, N. Typology of dairy cattle farming systems in the Gharb irrigated perimeter, Morroco. Archivos de Zootecnia, v.17, p.17-12, 2003.

STATISTICA versão 7.0. Statsoft, Inc., Tulsa, 2007. (CD-ROM).

ZANELA, M.B.; FISCHER, V.; RIBEIRO, M.E.R. et al. Qualidade do leite em sistemas de produção na região Sul do Rio Grande do Sul. Pesquisa Agropecuária Brasileira, v.41, n.1, p.153-159, 2006.

WEST, J.W. Effects of heat-stress on production in dairy cattle. Journal of Dairy Science, v.86, n.6, p.2131-2144, 2003. 